\title{
Shallow lakes theory revisited: various alternative regimes driven by climate, nutrients, depth and lake size
}

\author{
Marten Scheffer $\cdot$ Egbert H. van Nes
}

(C) Springer Science+Business Media B.V. 2007

\begin{abstract}
Shallow lakes have become the archetypical example of ecosystems with alternative stable states. However, since the early conception of that theory, the image of ecosystem stability has been elaborated for shallow lakes far beyond the simple original model. After discussing how spatial heterogeneity and fluctuation of environmental conditions may affect the stability of lakes, we review work demonstrating that the critical nutrient level for lakes to become turbid is higher for smaller lakes, and seems likely to be affected by climatic change too. We then show how the image of just two contrasting states has been elaborated. Different groups of primary producers may dominate shallow lakes, and such states dominated by a particular group may often represent alternative stable states. In tropical lakes, or small stagnant temperate waters, freefloating plants may represent an alternative stable state. Temperate shallow lakes may be dominated alternatively by charophytes, submerged angiosperms, green algae or cyanobacteria. The change of the lake communities along a gradient of
\end{abstract}

Guest editors: R. D. Gulati, E. Lammens, N. De Pauw \& E. Van Donk

Shallow lakes in a changing world

M. Scheffer $(\square) \cdot$ E. H. van Nes

Department of Aquatic Ecology and Water Quality

Management, Wageningen University, P.O. Box 8080,

6700 DD Wageningen, The Netherlands

e-mail: marten.scheffer@wur.nl eutrophication may therefore be seen as a continuum in which gradual species replacements are interrupted at critical points by more dramatic shifts to a contrasting alternative regime dominated by different species. The originally identified shift between a clear and a turbid state remains one of the more dramatic examples, but is surely not the only discontinuity that can be observed in the response of these ecosystems to environmental change.

\section{Keywords}

\section{Introduction}

Widespread problems resulting from eutrophication of shallow lakes in populated areas invoked numerous restoration projects in the last decades of the 20th century. However, even if the nutrient load to such lakes was strongly reduced they often did not recover to their original clear state (Sas, 1989). Research into the causes of this hysteresis has been surprisingly productive, not only in solving the restoration issue, but also in generating fundamental insights in the stability properties of these ecosystems (Moss, 1988; Jeppesen, 1998; Jeppesen et al., 1998; Scheffer, 1998). One of the most influential ideas that emerged from this work is arguably the theory that such lakes can be in two alternative stable states: clear with 
abundant submerged macrophytes or turbid with few submerged plants (Scheffer et al., 1993). The theoretical possibility that ecosystems could have alternative stable states had been noted long before (Lewontin, 1969; Holling, 1973; May, 1977), but shallow lakes are often considered the first well documented example.

This review highlights a few important new twists to the stability theory of lakes and points at some intriguing future questions. Although it is meant as an update for lake ecologists, we hope that some of the progress in the stability research on shallow lakes we report here may inspire scientists in related fields too.

\section{The alternative stable states theory of shallow lakes}

As a starting point let us resume the central ideas behind the original alternative stable states theory for shallow lakes (Scheffer et al., 1993). This theory was inspired by observations that lakes tended to shift rather abruptly between a clear and a turbid state, and that once lakes turned turbid, they subsequently resisted restoration efforts (Phillips et al., 1978; Meijer et al., 1989). Research revealed that both the turbid and the clear state were stabilized by a number of mechanisms (Moss, 1988; Jeppesen, 1998; Jeppesen et al., 1998; Scheffer, 1998). For instance, in the turbid state, fish promote phytoplankton growth by recycling nutrients and controlling the development of zooplankton that could otherwise help clear the water of phytoplankton. Also fish and waves may stir up sediments in shallow lakes with little or no vegetation. In this situation, light limitation and disturbance of the sediments make it difficult for submerged plants to settle. On the other hand, once submerged plants are abundant, they can greatly reduce turbidity by a suit of mechanisms resulting in control of excessive phytoplankton development and prevention of wave resuspension of sediments.

To illustrate how this mechanism may lead to alternative states, a simple graphical model suffices (Scheffer et al., 1993) (Fig. 1). The model is based on three assumptions:

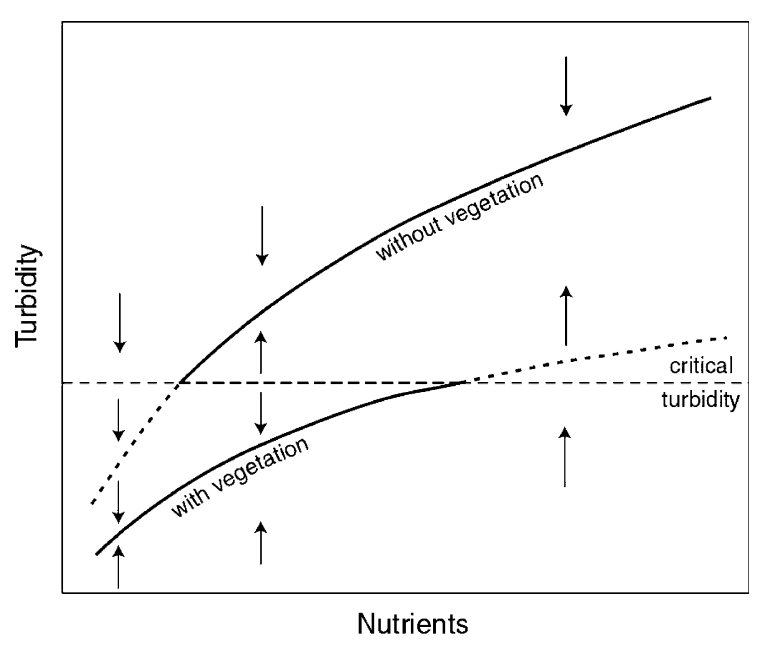

Fig. 1 Alternative equilibrium turbidities caused by disappearance of submerged vegetation when a critical turbidity is exceeded (see text for explanation). The arrows indicate the direction of change when the system is not in one of the two alternative stable states (from: Scheffer et al., 1993)

- Turbidity increases with the nutrient level due to increased phytoplankton growth.

- Vegetation reduces turbidity.

- Vegetation disappears when a critical turbidity is exceeded.

In view of the first two assumptions, equilibrium turbidity can be drawn as two different functions of the nutrient level one for a macrophyte dominated, and one for an unvegetated situation. Above a critical turbidity, macrophytes will be absent, in which case the upper equilibrium line is the relevant one and below this turbidity the lower equilibrium curve applies. The emerging picture shows that over a range of intermediate nutrient levels two alternative equilibria exist: one with macrophytes, and a more turbid one without vegetation. At lower nutrient levels, only the macrophyte-dominated equilibrium exists, whereas at the highest nutrient levels, there is only one equilibrium without vegetation.

This simple model allows an intuitive feeling for why the system can respond to environmental change showing hysteresis and catastrophic transitions. Gradual enrichment starting from low nutrient levels will cause the system to proceed 
along the lower equilibrium curve until the critical turbidity is reached at which macrophytes disappear. Now, a jump to a more turbid equilibrium at the upper part of the curve occurs. In order to restore the macrophyte dominated state by means of nutrient management, the nutrient level must be lowered to a value where phytoplankton growth is limited enough by nutrients alone to reach the critical turbidity for macrophytes again. At the extremes of the range of nutrient levels over which alternative stable states exist, either of the equilibrium lines approaches the critical turbidity that represents the breakpoint of the system. This corresponds to a decrease of stability. Near the edges, a small perturbation is enough to bring the system over the critical line and to cause a switch to the other equilibrium. Although this model illustrates how alternative stable states may arise, it is clearly a quite crude simplification of reality. In the following sections, we discuss some essential elaborations on this archetype model of alternative stable states in shallow lakes.

\section{Stability in the face of variation in space and time}

Clearly the image of alternative stable states in the simple model outlined above is a caricature. Seasonality is one complication (Scheffer et al., 1997a; Scheffer et al., 2001a), however as most systems have a "memory" in the winter time, seasonality will not necessarily change the behaviour of a model with alternative states if yearto-year changes are considered (Van Nes et al., 2002). On the other hand, chaotic population dynamics (Scheffer, 1991; Huisman \& Weissing, 1999) and the ever changing weather conditions also put the idea of a stable state in a different light (Scheffer \& Carpenter, 2003). It has been argued that in the face of such turmoil it is better to speak of alternative regimes than alternative stable states (Scheffer \& Carpenter, 2003). Another fundamental problem is that it is sometimes not so easy to demarcate the borders of a system. What if some parts of a lake are shallow and others deep? And what if clear and turbid lakes are connected?
Spatial heterogeneity

Perhaps the most obvious simplification in the basic graphical model (Fig. 1) is the assumption that all submerged plants disappear at a single critical turbidity. In practice, plants are less affected by turbidity at shallower sites. As a result, the shift from a vegetated state to the turbid state may occur less abrupt than predicted by the basic model. Vegetation will disappear more gradually, because the vegetation will be lost first from the deeper parts of the lake. Consequently hysteresis may be less pronounced (and can even disappear) if the depth profile of a lake is less flat (Van Nes et al., 2002). More in general, it has been shown for a range of ecological models that spatial heterogeneity of the environment tends to reduce the chance that large scale shifts between alternative stable states are found (Van Nes \& Scheffer, 2005). This seems intuitively straightforward as the shifts in the local states do not happen at the same moment, simply because different sites have different local properties. The numerous asynchronous shifts of different sites may be sharp individually, but average out over a larger region to give a smooth large-scale response rather than a drastic catastrophic shift. However, there is an interesting caveat in this reasoning. It all depends on the rate of 'mixing'. For instance, if water circulates through a lake rapidly, one expects the clearing effects of submerged plants to contribute to the overall change of turbidity in the lake, but not to result in a locally higher clarity. Analysis of different models shows that such mixing can counteract the smoothing effect of environmental heterogeneity, and cause the system to show large scale synchronous sharp shifts again (Van Nes \& Scheffer, 2005).

Data from some shallow lakes suggests that in practice, mixing can be surprisingly slow relative to the local clearing process in vegetation fields. As a result, alternative stable states can coexist side by side, despite an open connection. For instance, in the large (3,300 ha) and shallow (1.4 $\mathrm{m}$ average) Lake Veluwe, reduction of the nutrient load and increased fishing pressure triggered the recovery of marked fields with charophytes and locally very clear water that 
contrasted sharply with the turbid water in the rest of the lake (Scheffer et al., 1994; Van den Berg et al., 1998b; Lammens et al., 2004). The fields and the associated clear water patches expanded over the years until eventually the entire lake shifted to the clear state (Van den Berg et al., 1999).

\section{Non-equilibrium dynamics}

Although the original theory of alternative stable states in shallow lakes was used to understand the effects of occasional disturbances such as fish removal or extremes in the water level, it did not really address situations in which disturbances are the rule rather than the exception. Such high disturbance regimes are found for instance in cold climates where winter fish kills are common, or in places where desiccation of shallow lakes in summer is a frequent event (Scheffer et al., 2006). Clearly, such lakes will be far from any equilibrium most of the time. In fact, it has been argued that this may be true for ecological systems in general (Hastings, 2004). Although the image of 'alternative stable states' is clearly too simple to catch the essence of the dynamics of lakes under such severe disturbance regimes, it may be expanded to help seeing the big picture behind the dynamics.

In models, it can be shown that the duration of transients can be boosted if there are places or trajectories in the state space where the system tends to 'hang around' even if they do not represent attractors. Examples of such 'hangaround places' are saddle points, remainders of strange attractors and remainders of equilibria after saddle-node bifurcations (Strogatz, 1994). Probably, such slow transient dynamics can be important in nature too. Indeed, the tendency of some shallow lakes to stick to an unstable clear state for years, before sliding into the stable turbid state may be an example of such behavior. Lake Zwemlust, for example, stayed clear for about seven years upon fish removal, despite a very high nutrient concentration (Van Donk \& Gulati, 1995). Similarly, numerous Dutch floodplain lakes are in a clear state most of the time, despite high nutrient levels (Van Geest et al., in press). The idea here is that occasional droughts

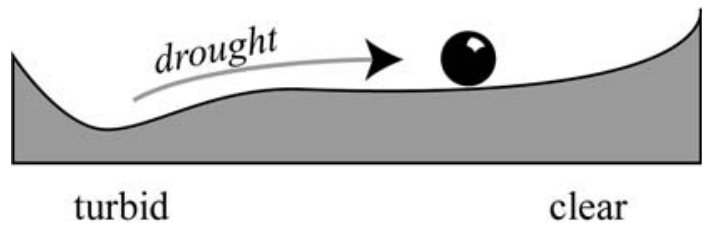

Fig. 2 Hypothesized dynamics of shallow floodplain lakes. Occasional droughts push the system to an unstable clear state that represents the ghost of a stable state. Since droughts happen every now and then, and the dynamics around such a ghost are very slow, the lake may be in a transient state most of the time. Note that the way to interpret such stability landscapes is that the movement of the ball is always damped. Imagine that the ball rolls through a heavily viscous fluid

result in almost complete desiccation of the lakes. This kills most of the fish and pushes the system into a clear situation, which is not stable, but the dynamics away from it are very slow (Fig. 2). Such transient state which may last for some years is called the 'ghost' of a stable state (Strogatz, 1994).

Cyclic shifts between alternative states

Although shifts between alternative states usually occur irregularly (Mitchell, 1989; Blindow, 1992; Blindow et al., 1993; Blindow et al., 2002), some lakes show remarkably regular oscillations between submerged plants and a turbid state. The best documented examples that we are aware of are the English lake Alderfen Broad (Moss et al., 1990; Perrow et al., 1994) and the Dutch Lake Botshol (Simons et al., 1994; Rip et al., 2005). Both lakes cycle between the alternative states with a period of approximately 7 years. Model analyses suggest that such cyclic behavior may arise under particular conditions from an internal 'time bomb' mechanism (Van Nes et al., in press), due to a slow negative effect of vegetation on the nutrient state of the lake (Fig. 3). If during the period of macrophyte dominance phosphorus retention is high and dead organic material accumulates on the sediment, decomposition may eventually cause anoxic conditions at the sediment surface, allowing phosphorus release that may promote a sufficient increase in phytoplankton to cause a decline of the submerged macrophytes. If subsequently the turbid state 


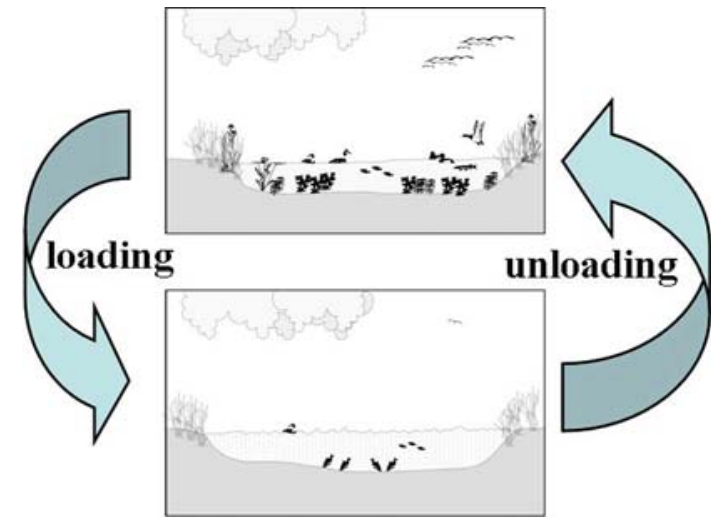

Fig. 3 Shallow lakes may under some conditions shift between a vegetated and a turbid state in a regular cyclic way due to intrinsic differences in accumulation of phosphorus and organic matter in the two states (see text for explanation)

allows sufficient decomposition of organic material and/or loss of phosphorus from the sediments, the lake may shift back to a clear macrophyte dominated state, and so forth. The model analyses suggest that such switching behavior can only occur in special cases, where the critical nutrient levels for both shifts are relatively close together and the negative effect of vegetation on the nutrient state is sufficiently strong (Van Nes et al., in press).

\section{Factors affecting the critical nutrient levels}

As eutrophication problems have been an important incentive for much of the work on shallow lakes, one of the central questions has always been what the critical nutrient level would be for maintaining a clear water state. Although this seems a straightforward question, one encounters some fundamental problems if one attempts to find the answer. Firstly, it is not so easy to assess the 'nutrient level' of a lake. For instance, although phosphorus is clearly important, nitrogen may play an important role in some cases too. Also, when it comes to phosphorus, much of what is available to the organisms in the long run is stored in the sediment (Sas, 1989; Carpenter, 2005). How much of that is reflected in total-P concentrations in the water column varies strongly with the presence of macrophytes and other biological factors. Thus, although we often use total-P as an indicator of the nutrient status of a lake, there are some caveats to that approach.

Perhaps more importantly, there are good reasons to believe that there is not one single critical nutrient level for maintaining clear water. Different lakes may vary widely in the nutrient level they can tolerate before they flip to a turbid condition. In principle, the list of factors that may influence the probability that a lake turns to the turbid state is almost endless. Here, we just highlight three important factors: lake depth, lake size and climate.

\section{Lake depth}

Besides nutrients, the most obvious factor that affects the probability of a lake to be dominated by submerged vegetation is its depth. In shallower water light conditions at the bottom are better, given that the optical properties of the water are the same. Also, plants can more easily grow to the surface layer of the water where they are relatively free of the shading effects of phytoplankton and suspended solids (Scheffer, 1998). This effect of water level can be easily linked to the simple graphical model of alternative states (Fig. 1) if one notes that the critical turbidity for plants depends on the water level. For instance, deeper water will move the critical turbidity for plants (the horizontal dashed line) downwards causing the critical nutrient level for both the forward switch and the backward switch to move to lower values. From an analysis of a more complex vegetation model this pattern is confirmed: the range of nutrient values with alternative states is much smaller in deeper water and eventually hardly any vegetation growth will be possible (Van Nes et al., 2002).

Importantly, the depth of a shallow lake can be subject to strong fluctuations resulting from climatic variability. Numerous observations highlight the importance of water level for shifts between a vegetation dominated state and a turbid state in shallow lakes. High water levels may lead to loss of submerged macrophytes, invoking a dramatic shift to a turbid state (Wallsten \& Forsgren, 1989; Engel \& Nichols, 1994). Also very low water level may have more 
complicated pronounced effects. For instance, desiccation and freezing of the lake bottom may in some cases damage the vegetation sufficiently to push a lake to a turbid state (Blindow et al., 1993). However, an opposite effect of low-water extremes is probably more common. The risk of fish kills due to anoxic conditions in summer or winter may become higher if the water level is low, leading to clear water conditions that promote subsequent vegetation dominance (Van Geest et al., 2003).

\section{Lake size}

A related but somehow more surprising factor that may have a large impact on the chances of a lake to be in a vegetation dominated clear state is lake size. Although lake size tends to be correlated to lake depth, size seems to have a considerable effect by itself too (Søndergaard et al., 2005). Small lakes appear to have a higher chance to be in a vegetated clear state. Although various factors may explain this correlation (Van Geest et al., 2003), suppression of fish in smaller lakes may be a common factor. Fish are rare in small, isolated lakes, probably as a result of a higher likelihood of fish kills combined with their low colonizing ability (Tonn \& Magnuson, 1982; Dahl, 1990; Magnuson et al., 1998; Hershey et al., 1999). Two recent studies exemplify this.

An analysis of 215 shallow lakes situated in the Dutch floodplain of the lower River Rhine (Van Geest et al., 2003) revealed particularly clear relationships between lake size, the abundance of fish and the presence of vegetation. All of these lakes are inundated about once a year by the eutrophic river; so nutrient loading varies relatively little among the lakes. In accordance with the theory, most of these lakes were either nearly devoid of vegetation or in a contrasting state with a rich plant community, but the likelihood of the richly vegetated state was higher in smaller lakes (other factors such as depth being equal) (Van Geest et al., 2003). These small vegetated lakes also supported low densities of benthivorous bream (Abramis brama) (Grift et al., 2001), the key fish species promoting the opposite poorlyvegetated, turbid state in shallow Dutch lakes (Scheffer, 1998).
Similarly, data from 796 Danish lakes and ponds (Søndergaard et al., 2005) showed overall low fish biomass below 1 ha, shifting to an often much higher biomass above this threshold. As in the Dutch lakes, macrophyte coverage was often highest in smaller lakes and ponds. This higher macrophyte coverage in small Danish lakes occurred despite a generally higher phosphorus content in the lake water related to a generally higher share of cultivated fields in the catchment (Søndergaard et al., 2005). Thus, the results from both the Dutch and Danish lakes suggest that small lakes are more likely to be fishless, which increases the likelihood of the clear-water state, even at quite high nutrient concentrations.

The higher chance for small water-bodies to be in a vegetated state also implies an interesting twist to the pattern of biodiversity that we would expect from classical 'island theory' (MacArthur \& Wilson, 1967). Species richness is predicted to be lower on small isolated (habitat-) islands than on similar sized pieces of mainland because small populations are more prone to extinction due to stochastic events, and because recolonization

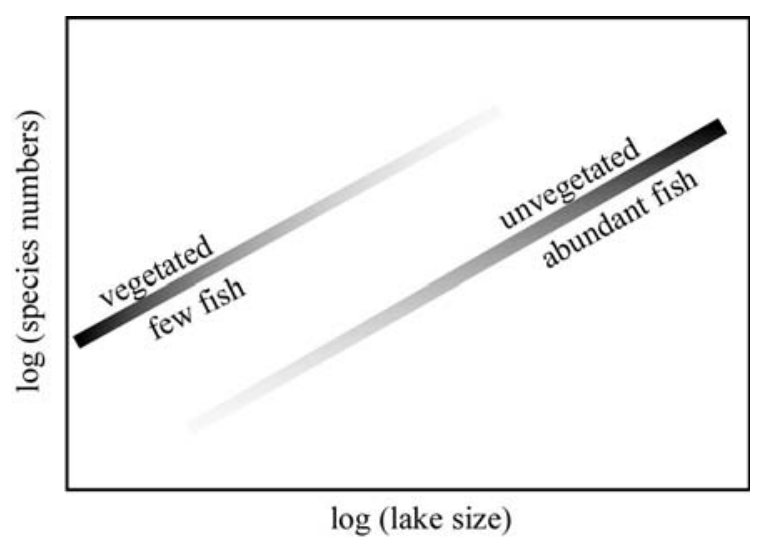

Fig. 4 Hypothesized effect of lake size on biodiversity. The graph is based on four assumptions (see text for background): (1) everything else being equal, species number tends to increase with lake size, (2) shallow lakes tend to be in either a fish-dominated, turbid state with few submerged plants, or in a state with few fish and usually high vegetation biomass, (3) overall, biodiversity is higher in a fish-poor vegetated lake than in a fish-dominated unvegetated lake of the same size, and (4) the likelihood of occurrence of the fish-poor, vegetated state decreases with lake size. The probability that a lake will be in either of two alternative states is represented by the darkness of the line (from: Scheffer et al., 2006) 
rates are lower in isolated locations. However, in shallow lakes the shift to a vegetated state may distort this pattern (Scheffer et al., 2006) (Fig. 4). Small lakes are more likely in a vegetationdominated state and such state implies an increase in food and habitat structures and consequently a higher biodiversity of birds invertebrates and amphibians (Jeppesen et al., 1997; Scheffer, 1998). Indeed, a recent survey comparing species diversity of macrophytes and invertebrates in ponds (65), lakes (4), ditches $(70 \mathrm{~km})$, streams $(28 \mathrm{~km})$ and rivers $(17 \mathrm{~km})$ in a British lowland landscape (Williams et al., 2004) shows that ponds exhibited considerably higher taxonomic richness, with more unique species and more scarce species than any of the other water body types.

\section{Climate}

An important unresolved question is what would be the impact of a warmer climate on the chances that shallow lakes fall in a turbid state. There are good reasons to expect that climate will have a large impact on shallow lakes. We know, for instance, that warmer conditions have a large effect on the 'trophic cascade' from fish to phytoplankton. In temperate conditions most fish reproduce only once a year, leaving a period in spring in which there are few small (juvenile) fish, allowing large zooplankton to become abundant and filter the water clear of phytoplankton (Sommer, 1986). By contrast, top-down control of zooplankton by fish is very strong all year round in warmer lakes at low latitudes because fish are abundant and reproduce continuously in such (sub)tropical lakes (Dumont, 1994). The difference in food web structure implies that biomanipulation as used to shift temperate lakes to a clear state, seems less easy to apply to (sub)tropical lakes (Scasso et al., 2001; Jeppesen et al., 2005).

Although climatic warming will not turn most temperate lake communities into subtropical ones, there are several other reasons to suspect that moderate warming might promote the turbid state in temperate lakes (Jeppesen et al., 2003). On the other hand, numerous field studies in temperate lakes suggest positive effects of warming on aquatic vegetation performance (Grace and Tilly, 1976; Best, 1987; Nelson, 1997; Scheffer et al., 1992; Rooney and Kalff, 2000) which would push the other way.

Importantly, climatic warming will also affect lake ecosystems through changes in hydrology and nutrient load to lakes, but findings so-far are rather contradictory (Weyhenmeyer, 2001; George, 2000; Monteith et al., 2000; Straile, 2002). An interesting aspect of climatic impact is that systems with alternative stable states even brief climatic extremes may induce a shift to another state in which the system subsequently remains for a long time (Scheffer et al., 2001b). Indeed, there are indications that shallow lakes may be affected by climatic extremes in this way (Scheffer, 1998). For instance, heavy storms have induced a shift to a permanent turbid state by destroying vegetation (McKinnon and Mitchell, 1994; Schelske and Brezonik, 1992). However, perhaps the most important potential impact of climatic extremes is can be through their effect on water level fluctuations to which these lakes are very sensitive as mentioned before. Clearly, the issue of climatic effects is far from resolved, but numerous studies are underway that will certainly resolve some key-issues over the coming years.

\section{Other alternative stable states in aquatic systems}

The previous section shows that it has become increasingly clear that many factors may play a role in determining whether a shallow lake is in a turbid state or in a clear-water state dominated by submerged plants. However, it is becoming clear that shallow lakes may be in more than just those two alternative stable states. One potential source of alternative attractors in freshwater as well as marine systems is the interaction of competitors and predators in size-structured fish communities, often analysed by means of individual-based models (DeAngelis \& Gross, 1992; De Roos \& Persson, 2002). For instance, overexploitation of a predatory fish such as cod may be irreversible if a good stock of adults is needed to crop down the potential competitors/predators of their own offspring (Walters \& Kitchell, 2001). More apparent in shallow lakes is the phenomenon that different primary producers may dominate the system. In 
addition to dominance by submerged angiosperms, versus the turbid state dominated by $a$ mixed phytoplankton community of green algae and other groups, it has now been suggested that dominance by free-floating plants, charophytes, and filamentous cyanobacteria also appear to have the character of a self-stabilizing condition in some lakes. Here we briefly point at some recent work on stability of these states.

Floating plant dominance

Although a turbid state with high phytoplankton biomass is the typical eutrophication problem in temperate lakes, invasion by mats of free-floating plants is among the most important threats to the functioning and biodiversity of freshwater ecosystems ranging from temperate ponds and ditches (Janse \& Van Puijenbroek, 1998) to large tropical lakes (Gopal, 1987; Mehra et al., 1999). Dark, anoxic conditions under a thick floating plant cover leave little opportunity for animal or plant life. In tropical lakes large floating species and in particular the water hyacinth (Eichhornia crassipes), have dramatic negative impacts on fisheries and navigation (Gopal, 1987; Mehra et al., 1999). Not surprisingly, resolving floating plant problems has a high priority in many warm regions of the world, and is also a focus of quality management of many smaller water bodies in temperate regions. For example, in the extensive system of ditches and canals in the Netherlands, duckweeds are considered the main problem associated to eutrophication (Janse \& Van Puijenbroek, 1998).

It has been demonstrated that a shift to floating plant dominance in shallow water ecosystems is a highly non-linear phenomenon (Scheffer et al., 2003). Just like the shift to a turbid state in temperate lakes, the shift to floating plant dominance is difficult to reverse and can happen when a critical threshold level of nutrients is passed. The explanation is in the way the floating plants compete with submerged plants. Floating plants have primacy in competition for light but need high nutrient concentrations (Portielje \& Roijackers, 1995). By contrast, rooted submerged macrophytes are susceptible to shading, but less dependent on nutrients in the water column as they may take up a large part of their nutrients from the sediment (Hutchinson, 1975; Chambers et al., 1989). Still submerged plants can also use their shoots effectively for nutrient uptake from the water column (Sculthorpe, 1967; Robach et al., 1996) and by various mechanisms reduce nitrogen concentrations in the water column to below detection levels (Goulder, 1969; Van Donk et al., 1993). This interaction may result in two alternative stable states: a floating plant dominated state in which invasion by submerged plants is prevented by shading, and a situation dominated by submerged plants in which invasion by free-floating plants is prevented by reduced nutrient availability (Scheffer et al., 2003). This bistability makes reversal of floating plant invasion of a lake often difficult. On the other hand it implies that if nutrient levels have been sufficiently reduced, a one-time removal of floating plants might tip the balance to an alternative stable state dominated by submerged plants.

\section{Charophyte dominance}

In addition to setting the free-floating plants apart, a distinction into at least two groups may be made in the submerged macrophytes. Although there are many species of submerged macrophytes, one particular group differs rather fundamentally from the rest. Charophytes (stoneworts) are not only distinct taxonomically (they are algae rather than Angiosperms), but also ecologically. In some lakes distinct shifts from pondweeds to an almost complete monoculture of charophytes has been observed (Hargeby et al., 1994; Van den Berg et al., 1999). This suggests that co-existence of these two groups may be unstable, and their competition might suggest in alternative stable states of dominance by either of the groups.

To test this idea Van Nes, Van den Berg and others (2003) have looked more deeply into the competition between two particular representatives of these groups: Chara aspera Deth. ex Willd. and pondweed Potamogeton pectinatus L.. Just as in the Swedish Lake Krankesjön (Hargeby et al., 1994), the shift from a turbid to a clear state in Lake Veluwe were this research group worked, proceeded really through an intermediate phase 
dominated by pondweeds to a really clear state dominated by stoneworts (Van den Berg et al., 1999). Looking into the mechanistic details of competition, it appears that there is an interesting asymmetry much like the one discussed for floating plants versus submerged plants. In the case of pondweeds and Chara, the tall, canopyforming pondweed ( $P$. pectinatus) is simply on top of the short charophyte (C. aspera), and therefore pondweed is the better competitors for light (Van den Berg et al., 1998a). However, it appears that the stonewort is strongly depleting bicarbonate, and can at the same time survive at lower bicarbonate concentrations (Van den Berg, 1999). Thus there is a positive feedback in the development of the stonewort as it drives the system towards carbon limitation, suppressing the pondweed, and thereby creating better light conditions for itself (Van Nes et al., 2003). A detailed individual based competition model suggests that this may plausibly lead to alternative stable states in the competition between these two submerged macrophytes (Van Nes et al., 2003).

\section{Cyanobacterial dominance}

The previous sections illustrate that it is too simple to consider aquatic macrophytes, or even submerged macrophytes as a single group. The same is true for phytoplankton. Different species can rise to dominance, and despite intensive research and growing insight in the factors that drive succession we are still far from able to predict which species will dominate when. Perhaps the best-studied group are blue-green algae. Of course these are really bacteria (cyanobacteria) rather than algae, but as planktonic autotrophs they occupy the same niche. Species in this group differ widely, and it is impossible to treat them as a single ecological entity. However, some groups have been studied more than others, as they are often a nuisance. In shallow lakes, filamentous cyanobacteria of the Oscillatoria group can be dominant all year round. These cyanobacteria are rather shade tolerant, which explains why they enter especially when the water has become sufficiently turbid (Mur et al., 1993). Interestingly, they can also intensify the shady conditions once they are present. This is because with the same amount of phosphorus they can build biomass that causes a relatively high light attenuation (Mur et al., 1977). As a result, they can stabilize their dominance once they are there, creating an alternative stable state in the phytoplankton community (Scheffer et al., 1997b). On the other hand their maximum growth is less than of most other algae. Therefore in less turbid conditions groups such as green algae have a competitive advantage and can become dominant over blue-green algae.

\section{Conclusion}

In conclusion, while the essence of the original theory of alternative stable states in shallow lakes remains quite valid to explain major patterns of change, numerous expansions of the basic idea have been suggested. It has been shown that there is no single critical nutrient level for maintaining a clear state, as factors such as lake size, depth and climate affect the threshold. Moreover, the image of just two contrasting states has been elaborated. While the contrast between submerged macrophytes and a turbid phytoplankton dominated state remains perhaps the most spectacular, many other less conspicuous shifts between alternative states seem to occur in reality. Therefore, the change of the biological communities along a gradient of eutrophication may really be seen as a continuum in which gradual species replacements are interrupted at critical points by moderate or more dramatic shifts to a contrasting community state. Spatial heterogeneity and the interplay of internal cyclic or chaotic dynamics with the effects of fluctuating climatic conditions and hydrology further complicate the matter to the point that it may all seem hopelessly complex again. The challenge, as always in ecology, is to keep seeing the big patterns without being ignorant about the details. In this sense, we feel that shallow lake ecology is actually in quite good shape. Many details can be explained, whereas at the same time, the mechanisms that cause major patterns such as dominance by submerged plants, cyanobacteria or floating plants have been identified. On the other hand, we are still uncertain 
about many processes and we may rightly feel that we have just seen the tip of the iceberg when it comes to really understanding the full complexity of shallow lake ecosystems. Nonetheless, shallow lakes are really well understood if we compare our insights to what is known about oceans, forests and other vast ecosystems of the world. Indeed, shallow lakes have served as an example to illustrate stability aspects that may be important in many other systems where they cannot be studied so easily (Gunderson \& Holling, 2001; Scheffer et al., 2001b; Folke et al., 2004). We feel that shallow lakes will proceed to play this important role in ecology, considering the exiting new developments in shallow lake science.

\section{References}

Best, E. P. H., 1987. The submerged macrophytes in Lake Maarsseveen I, the Netherlands: changes in species composition and biomass over a six-year period. Hydrobiology Bulletin 21: 55-60.

Blindow, I., 1992. Long- and short-term dynamics of submerged macrophytes in two shallow eutrophic lakes. Freshwater Biology 28: 15-27.

Blindow, I., A. Hargeby \& G. Andersson, 2002. Seasonal changes of mechanisms maintaining clear water in a shallow lake with abundant Chara vegetation. Aquatic Botany 72: 315-334.

Blindow, I., G. Andersson, A. Hargeby \& S. Johansson, 1993. Long-term pattern of alternative stable states in two shallow eutrophic lakes. Freshwater Biology 30: 159-167.

Carpenter, S. R., 2005. Eutrophication of aquatic ecosystems: bistability and soil phosphorus. Proceedings of the National Academy of Science of the United States of America 102: 10002-10005.

Chambers, P. A., E. E. Prepas, M. L. Bothwell \& H. R. Hamilton, 1989. Roots versus shoots in nutrient uptake by aquatic macrophytes in flowing waters. Candian Journal of Fisheries and Aquatic Sciences 46: 435-439.

Dahl, T. E., 1990, Wetland losses in the United States, 1780 's to 1980 's. U.S. Department of the Interior, Fish and Wildlife Service, Washington DC.

De Roos, A. M. \& L. Persson, 2002. Size-dependent lifehistory traits promote catastrophic collapses of top predators. Proceedings of the National Academy of Science of the United States of America 99: 1290712912.

DeAngelis, D. L., \& L. J. Gross, 1992, Individual-based models and approaches in ecology. Chapman and Hall, New York, 1-525.

Dumont, H. J., 1994. On the diversity of the cladocera in the tropics. Hydrobiologia 272: 27-38.
Engel, S. \& S. A. Nichols, 1994. Aquatic macrophyte growth in a turbid windswept lake. Journal of Freshwater Ecology 9: 97-109.

Folke, C., S. Carpenter, B. Walker, M. Scheffer, T. Elmqvist, L. Gunderson \& C. S. Holling, 2004. Regime shifts, resilience, and biodiversity in ecosystem management. Annual Review of Ecology Evolution and Systematics 35: 557-581.

George, D. G., 2000. The impact of regional-scale changes in the weather on the long-term dynamics of Eudiaptomus and Daphnia in Esthwaite Water, Cumbria. Freshwater Biology 45: 111-121.

Gopal, B., 1987, Water hyacinth. Elsevier, New York.

Goulder, R., 1969. Interactions between the rates of production of a freshwater macrophyte and phytoplankton in a pond. Oikos 20: 300-309.

Grace, J. B. \& L. J. Tilly, 1976. Distribution and abundance of submerged macrophytes, including Myriophyllum spicatum L. (Angiospermae), in a cooling reservoir. Archiv für Hydrobiologie 77: 475-487.

Grift, R. E., A. D. Buijse, W. L. T. Van Densen \& J. G. P. Klein Breteler, 2001. Restoration of the river-floodplain interaction: benefits for the fish community in the River Rhine. Archiv für Hydrobiologie 135: 173185.

Gunderson, L. \& C. S. Holling, 2001. Panarchy: understanding transformations in human and natural systems. Island Press, Washington.

Hargeby, A., G. Andersson, I. Blindow \& S. Johansson, 1994. Trophic web structure in a shallow eutrophic lake during a dominance shift from phytoplankton to submerged macrophytes. Hydrobiologia 280: 83-90.

Hastings, A., 2004. Transients: the key to long-term ecological understanding? Trends in Ecology \& Evolution 19: 39-45.

Hershey, A. E., G. M. Gettel, M. E. McDonald, M. C. Miller, H. Mooers, W. J. O'Brien, J. Pastor, C. Richards \& J. A. Schuldt, 1999. A geomorphic-trophic model for landscape control of Arctic lake food webs. Bioscience 49: 887-897.

Holling, C. S., 1973. Resilience and stability of ecological systems. Annual Review of Ecology and Systematics 4: 1-23.

Huisman, J. \& F. J. Weissing, 1999. Biodiversity of plankton by species oscillations and chaos. Nature 402: 407-410.

Hutchinson, G. E., 1975, A treatise on limnology. Vol. III, limnological botany. John Wiley \& Sons, New York.

Janse, J. H. \& P. J. T. M. Van Puijenbroek, 1998. Effects of eutrophication in drainage ditches. Environmental Pollution 102: 547-552.

Jeppesen, E., 1998. The ecology of shallow lakes - Trophic Interactions in the Pelagial. University of Copenhagen, Silkeborg, 358.

Jeppesen, E., M. Søndergaard \& J. P. Jensen, 2003. Climate warming and regime shifts in lake food webs - some comments. Limnology and Oceanography 48: 1346-1349.

Jeppesen, E., M. Søndergaard, M. Søndergaard, \& K. Kristoffersen, 1998, Structuring role of submerged macrophytes in lakes. Springer-Verlag, New York. 
Jeppesen, E., J. P. Jensen, M. Søndergaard, T. Lauridsen, L. J. Pedersen \& L. Jensen, 1997. Top-down control in freshwater lakes: the role of nutrient state, submerged macrophytes and water depth. Hydrobiologia 342: 151-164.

Jeppesen, E., M. Søndergaard, N. Mazzeo, M. Meerhoff, C. Branco, V. Huszar \& F. Scasso, 2005. Lake restoration and biomanipulation in temperate lakes: relevance for subtropical and tropical lakes. In Reddy, M. V. (ed.), Restoration and Management of Tropical Eutrophic Lakes. Science Publishers.

Lammens, E. H. R. R., M. L. Meijer, E. H. Van Nes \& M. S. Van den Berg, 2004. Effects of commercial fishery on the bream population and the expansion of Chara aspera in Lake Veluwe. Ecological Modelling 177: 233-244.

Lewontin, R. C., 1969. The meaning of stability. Diversity and stability in ecological systems: report of a symposium held May 26-28. 13-24.

MacArthur, R. H., \& E. O. Wilson, 1967, The theory of island biogeography. Princeton University Press, Princeton, 203.

Magnuson, J. J., W. M. Tonn, A. Banerjee, J. Toivonen, O. Sanchez \& M. Rask, 1998. Isolation vs. extinction in the assembly of fishes in small northern lakes. Ecology 79: 2941-2956.

May, R. M., 1977. Thresholds and breakpoints in ecosystems with a multiplicity of stable states. Nature 269: 471-477.

McKinnon, S. L. \& S. F. Mitchell, 1994. Eutrophication and black swan (Cygnus atratus Latham) populations: tests of two simple relationships. Hydrobiologia 279280: 163-170.

Mehra, A., M. E. Farago, D. K. Banerjee \& K. B. Cordes, 1999. The water hyacinth: an environmental friend or pest? A review. Resource Environmental Biotechnology 2: 255-281.

Meijer, M. L., A. J. Raat \& R. W. Doef, 1989. Restoration by biomanipulation of Lake Bleiswijkse Zoom the Netherlands first results. Hydrobiology Bulletin 23: 49-58.

Mitchell, S. F., 1989. Primary production in a shallow eutrophic lake dominated alternately by phytoplankton and by submerged macrophytes. Aquatic Botany 33: $101-110$.

Monteith, D. T., C. D. Evans \& B. Reynolds, 2000. Are temporal variations in the nitrate content of UK upland freshwaters linked to the North Atlantic Oscillation? Hydrological Processes 14: 1745-1749.

Moss, B., 1988, Ecology of fresh waters, 2nd edn. Man \& Medium. Blackwell Scientific, Oxford, 1-400.

Moss, B., J. Stansfield \& K. Irvine, 1990. Problems in the restoration of a hypertrophic lake by diversion of a nutrient-rich inflow. Verhandlungen Internationale Vereinigung Theoretisch Angewandte Limnologie 24: 568-572.

Mur, L. R., H. J. Gons \& L. Van Liere, 1977. Some experiments on competition between green-algae and blue- green bacteria in light-limited environments. FEMS Microbiology Letters 1: 335-338.
Mur, L. R., H. Schreurs \& P. Visser, 1993. How to control undesirable cyanobacterial dominance. In Giussani, G. \& C. Callieri (eds), Proceedings of the 5th international conference on the conservation and management of lakes, Stresa, Italy, 565-569.

Nelson, T. A., 1997. Interannual variance in a subtidal eelgrass community. Aquatic Botany 56: 245-252.

Perrow, M. R., B. Moss \& J. Stansfield, 1994. Trophic interactions in a shallow lake following a reduction in nutrient loading - A long-term study. Hydrobiologia 276: 43-52.

Phillips, G. L., D. Eminson \& B. Moss, 1978. A mechanism to account for macrophyte decline in progressively eutrophicated fresh waters. Aquatic Botany 4: 103126.

Portielje, R. \& R. M. M. Roijackers, 1995. Primary succession of aquatic macrophytes in experimental ditches in relation to nutrient input. Aquatic Botany 50: $127-140$.

Rip, W. J., M. Ouboter, B. Beltman \& E. H. Van Nes, 2005. Oscillation of a shallow lake ecosystem upon reduction in external phosphorus load. Archiv fur Hydrobiologie 164: 387-409.

Robach, F., S. Merlin, T. Rolland \& M. Tremolieres, 1996. Ecophysiological approach of water quality bioindicating using aquatic plant materials: the role of phosphorus. Ecologie-Brunoy 27: 203-214.

Rooney, N. \& J. Kalff, 2000. Inter-annual variation in submerged macrophyte community biomass and distribution: the influence of temperature and lake morphometry. Aquatic Botany 68: 321-335.

Sas, H., 1989, Lake restoration by reduction of nutrient loading: expectations, experiences, extrapolations. Academia Verlag Richarz, St. Augustin, 1-497.

Scasso, F., N. Mazzeo, J. Gorga, C. Kruk, G. Lacerot, J. Clemente, D. Fabian \& S. Bonilla, 2001. Limnological changes in a sub-tropical shallow hypertrophic lake during its restoration: two years of a whole-lake experiment. Aquatic Conservation-Marine Freshwater Ecosystem 11: 31-44.

Scheffer, M., 1991. Should we expect strange attractors behind plankton dynamics: And if so, should we bother? Journal of Plankton Research 13: 1291-1306.

Scheffer, M., 1998. Ecology of shallow lakes. Chapman and Hall, London, 0-357.

Scheffer, M. \& S. R. Carpenter, 2003. Catastrophic regime shifts in ecosystems: linking theory to observation. Trends in Ecology \& Evolution 18: 648-656.

Scheffer, M., M. R. De Redelijkheid \& F. Noppert, 1992. Distribution and dynamics of submerged vegetation in a chain of shallow eutrophic lakes. Aquatic Botany 42: 199-216.

Scheffer, M., S. Rinaldi, Y. A. Kuznetsov \& E. H. Van Nes, 1997a. Seasonal dynamics of Daphnia and algae explained as a periodically forced predator-prey system. Oikos 80: 519-532.

Scheffer, M., D. Straile, E. H. Van Nes \& H. Hosper, 2001a. Climatic warming causes regime shifts in lake food webs. Limnology and Oceanography 46: 17801783. 
Scheffer, M., S. H. Hosper, M. L. Meijer, B. Moss \& E. Jeppesen, 1993. Alternative equilibria in shallow lakes. Trends in Ecology and Evolution 8: 275-279.

Scheffer, M., S. Rinaldi, A. Gragnani, L. R. Mur \& E. H. Van Nes, 1997b. On the dominance of filamentous cyanobacteria in shallow, turbid lakes. Ecology 78: 272-282.

Scheffer, M., S. R. Carpenter, J. A. Foley, C. Folke \& B. Walker, 2001. Catastrophic shifts in ecosystems. Nature 413: 591-596.

Scheffer, M., M. S. Van den Berg, A. W. Breukelaar, C. P. M. Breukers, H. Coops, R. W. Doef \& M. L. Meijer, 1994. Vegetated areas with clear water in turbid shallow lakes. Aquatic Botany 49: 193-196.

Scheffer, M., S. Szabo, A. Gragnani, E. H. van Nes, S. Rinaldi, N. Kautsky, J. Norberg, R. M. M. Roijackers \& R. J. M. Franken, 2003. Floating plant dominance as a stable state. Proceedings of the National Academy of Science of the United States of America 100: 4040-4045.

Scheffer, M., G. J. Van Geest, K. Zimmer, E. Jeppesen, M. Søndergaard, M. G. Butler, M. A. Hanson, S. Declerck \& L. De Meester, 2006. Small habitat size and isolation can promote species richness: second-order effects on biodiversity in shallow lakes and ponds. Oikos 112: 227-231.

Schelske, C. L. \& P. Brezonik, 1992. Can Lake Apopka be restored? In Maurizi, S. \& F. Poillon (eds), Restoration of Aquatic Ecosystems. National Academic Press, Washington D.C.: 393-398.

Sculthorpe, C. D., 1967, The biology of aquatic vascular plants. Edward Arnold Ltd., London.

Simons, J., M. Ohm, R. Daalder, P. Boers \& W. Rip, 1994. Restoration of Botshol (the Netherlands) by reduction of external nutrient load -recovery of a characean community, dominated by Chara connivens. Hydrobiologia 276: 243-253.

Sommer, U., 1986. The periodicity of phytoplankton in Lake Constance (Bodensee) in comparison to other deep lakes of central Europe. Hydrobiologia 138: 1-8.

Søndergaard, M., E. Jeppesen \& J. P. Jensen, 2005. Pond or lake: does it make any difference? Archiv Fur Hydrobiologie 162: 143-165.

Straile, D., 2002. North Atlantic Oscillation synchronizes food-web interactions in central European lakes. Proceedings of the Royal Society of Edinburgh. Section B (Biological Sciences) 269: 391-395.

Strogatz, S. H., 1994, Nonlinear dynamics and chaos - with applications to physics, biology, chemistry and engineering. Addison-Wesley Publishing Company, Reading, 1-498.

Tonn, W. M. \& J. J. Magnuson, 1982. Patterns in the species composition and richness of fish assemblages in northern Wisconsin Lakes. Ecology 63: 1149-1166.

Van den Berg, M. S., 1999. A comparative study of the use of inorganic carbon resources by Chara aspera and Potamogeton pectinatus. In Van den Berg, M. S. (ed.), Charophyte recolonization in shallow lakes processes, ecological effects and implications for lake management. Thesis Vrije Universiteit Amsterdam, 57-67.
Van den Berg, M. S., H. Coops, J. Simons \& A. De Keizer, 1998a. Competition between Chara aspera and Potamogeton pectinatus as a function of temperature and light. Aquatic Botany 60: 241-250.

Van den Berg, M. S., M. Scheffer, E. H. Van Nes \& H. Coops, 1999. Dynamics and stability of Chara sp and Potamogeton pectinatus in a shallow lake changing in eutrophication level. Hydrobiologia 409: 335-342.

Van den Berg, M. S., H. Coops, M. L. Meijer, M. Scheffer \& J. Simons, 1998b. Clear water associated with a dense Chara vegetation in the shallow and turbid Lake Veluwemeer, the Netherlands. In Jeppesen, E., M. Søndergaard, M. Søndergaard \& K. Kristoffersen (eds), Structuring Role of Submerged Macrophytes in Lakes. Springer-Verlag, New York, 339-352.

Van Donk, E. \& R. D. Gulati, 1995. Transition of a lake to turbid state six years after biomanipulation: mechanisms and pathways. Water Science and Technology 32: 197-206.

Van Donk, E., R. D. Gulati, A. Iedema \& J. T. Meulemans, 1993. Macrophyte-related shifts in the nitrogen and phosphorus contents of the different trophic levels in a biomanipulated shallow lake. Hydrobiologia 251: 19-26.

Van Geest, G. J., H. Coops, M. Scheffer \& E. H. van Nes, in press. Transient macrophyte dominance in lakes with fluctuating water levels. Ecosystems.

Van Geest, G. J., F. Roozen, H. Coops, R. M. M. Roijackers, A. D. Buijse, E. Peeters \& M. Scheffer, 2003. Vegetation abundance in lowland flood plan lakes determined by surface area, age and connectivity. Freshwater Biology 48: 440-454.

Van Nes, E. H. \& M. Scheffer, 2005. Implications of spatial heterogeneity for regime shifts in ecosystems. Ecology 86: 1797-1807.

Van Nes, E. H., W. J. Rip \& M. Scheffer, in press. A theory for cyclic shifts between alternative states in shallow lakes. Ecosystems.

Van Nes, E. H., M. Scheffer, M. S. Van den Berg \& H. Coops, 2002. Dominance of charophytes in eutrophic shallow lakes - when should we expect it to be an alternative stable state? Aquatic Botany 72: 275-296.

Van Nes, E. H., M. Scheffer, M. S. Van den Berg \& H. Coops, 2003. Charisma: a spatial explicit simulation model of submerged macrophytes. Ecological Modelling 159: 103-116.

Wallsten, M. \& P. O. Forsgren, 1989. The effects of increased water level on aquatic macrophytes. Journal of Aquatic Plant Management 27: 32-37.

Walters, C. \& J. F. Kitchell, 2001. Cultivation/depensation effects on juvenile survival and recruitment: implications for the theory of fishing. Canadian Journal of Fisheries and Aquatic Sciences 58: 39-50.

Weyhenmeyer, G. A., 2001. Warmer winters: are planktonic algal populations in Sweden's largest lakes affected? Ambio 30: 565-571.

Williams, P., M. Whitfield, J. Biggs, S. Bray, G. Fox, P. Nicolet \& D. Sear, 2004. Comparative biodiversity of rivers, streams, ditches and ponds in an agricultural landscape in Southern England. Biological Conservation 115: 329-341. 